\title{
ARCHEOLOGISCHE KRONIEK
}

\author{
door
}

\author{
M. DESITTERE
}

\section{A. OPGRAVINGEN EN VONDSTEN : DE GALLO-ROMEINSE PERIODE (II) ${ }^{1}$}

\section{Destelbergen}

In 1960 ondernam het Seminarie voor Archeologie Gent een proefgraving op de plaats Eenbeekeinde. Vanaf 1965 verliepen de opgravingen jaarlijks in één of meerdere campagnes. Over de stand van het onderzoek voor wat de voorgeschiedenis betreft hadden wij het reeds in een voorgaande kroniek (Desittere 1974, pp. 143-144). Belangrijker, zeker in het licht van de wordingsgeschiedenis van het oude Gent, zijn de resultaten over de bewoning van het site in de Gallo-Romeinse periode. Door de systematische opgravingen op de plaats Eenbeekeinde winnen ook de vroegere vondsten, die elders op de gemeente Destelbergen werden gedaan, aan belang. Ze zullen verder in deze kroniek besproken worden.

In de oudere literatuur worden heelwat van deze vondsten gelocaliseerd op de plaats Steenland terwijl anderzijds de resten van wat hoogstwaarschijnlijk een muntschat is geweest, gesitueerd worden op de plaats BerkenZant. Beide toponymen zijn thans verdwenen maar konden we terugvinden op een kaart van Carolus Benthuys ( -1771$)$. We geven hier een uittreksel van deze kaart weer waarop het terrein van de huidige opgravingen (nr. 1 op de kaart) gesitueerd wordt t.o.v. de vindplaats Steenland (nr. 2 op de kaart) en van de plaats Berken-Zant (nr. 3 op de kaart).

Voor wat de resultaten van het systematische onderzoek op Eenbeekeinde betreft, verwijzen we de lezer naar de basisliteratuur, de opgravingsverslagen en laboratoriumanalyses, gepubliceerd in O.O.V.O. (II, 1961, pp. 38-54 ; III, 1964, pp. 27-71 ; IV, 1967, pp. 129-165 ; V, 1970, pp. 23-186 ; VII, 1976, pp. 21-72 ; VIII, 1978, pp. 17-29, 31-61).

Beknopte samenvattingen van deze verslagen zijn te vinden in de archeologische kronieken (distrikt E) van het tijdschrift Helinium (Helinium 4, 1964, p. 63 ; 7, 1967, Pp. $85-86$; 10, 1970, Pp. $159-161 ; 13,1973$, pp. $195-196 ; 16,1976$, pp. 79,84$)$.

Meer gespecialiseerde onderwerpen of deelaspecten worden behandeld in volgende werken :

Boon 1973 (kruiken en kruikamforen).

De Laet 1966 (zeepwaar - aardewerk).

(1) De nummering van de vondsten sluit aan bij deze uit de voorgaande kroniek (Desittere 1977, pp. 225-239). 

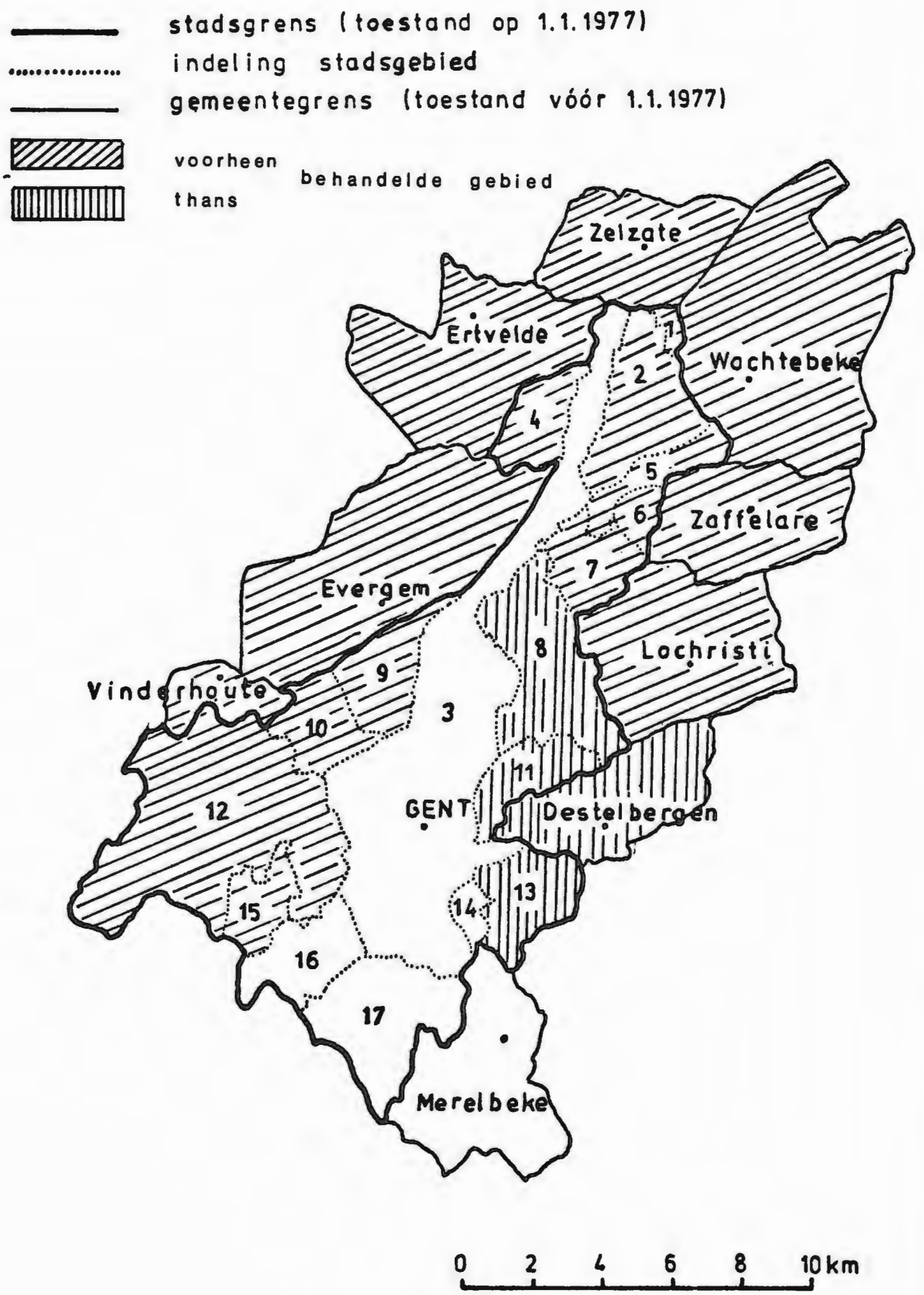
De Laet - Van Doorselaer 1969 (lokale ijzerwinning).

De Laet - Thoen 1969 (Pompejaans - rood aardewerk).

De Laet - Thoen - Van Doorselaer 1970 (massagraf).

Van Doorselaer 1969 (brandrestengraven).

- 1971 (ijzerwinning).

Vynckier 1966 (vlechtwerk uit lindenbast).

Als synthetische overzichten met bijzondere aandacht voor de GalloRomeinse oorsprong van de stad Gent vermelden we tenslotte :

De Laet 1969 a.

- 1969 b.

- 1977.

Wankenne 1972, Pp. 38-40.

\section{Destelbergen}

a. Op de plaats Steenland.

b. Aardewerk.

c. Bewaarplaats : onbekend. In 1847 in het bezit van dhr. Schayes (zie opmerking).

d. Bibliografie :

- Verhelst 1847, p. 78, nr. 1482.

- Schuermans 1872 , p. 31.

- Bauwens-Lesenne 1962, p. 69 (verkeerdelijk onder Gent besproken).

Opmerking: op de kaart van Benthuys (1771) is Steenland gelegen tussen de Leeghen Herrewegh en de Schelde enerzijds, de Eembeke en de Leede anderzijds (nr. 2 op de kaart). Op het moderne stratennet kan Steenland nauwkeurig gesitueerd worden als gelegen ten zuiden van de Nijverheidsstraat (Leeghen Herrewegh), ten noorden van de Schelde en ten westen van de Panhuisstraat. De voorwerpen maakten eerst deel uit van de verzameling J. Versturme-Roegiers (Gent). Een geinterfoliëerd exemplaar van de veilingscatalogus van deze verzameling (Verhelst 1847), bewaard in de Centrale Bibliotheek van de Rijksuniversiteit Gent onder nr. G.10609, leert ons dat de voorwerpen werden opgekocht door de heer Schayes. Van dan af zijn we hun spoor bijster.

\section{Destelbergen}

a. In 1823 op de plaats Steenland, bij het Pannenhuis.

b. Vijf stuks terra sigillata en een scherf van Pompejaans-rood aardewerk. De hier volgende beschrijvingen en identificaties steunen op De Clippele (zie bibliografie).

1. T.S.-wandscherf van Dr. 37 (fig. 1) ; rode, hard gebakken klei ; doffe, rode vernis; spiralenfries met erboven achterste poten en opstaande staart van lopend dier.

Trier, einde $2 e$ eeuw - begin $3 e$ eeuw.

2. T.S.-bodemstuk van Dr. 37 of 38 (fig. 2 en 10); goed gebakken roze klei ; matte, rode vernis; stempel : IVLLINIM.

Iullinus van Lezoux; periode : Flaviërs-Antonijnen.

3. Middendoor gebroken exemplaar van Dr. $18 / 31$ (fig. 4 en 11); h : $49 \mathrm{~mm}$; diam. rand : $170 \mathrm{~mm}$; diam. bodem : $90 \mathrm{~mm}$; roze, 
goed gebakken klei; matte, rode vernis; restant van stempel : I M... Lezoux, einde $1 \mathrm{e}$ - begin $2 \mathrm{e}$ eeuw.

4. Middendoor gebroken exemplaar van Dr. 33 (fig. 3) ; h: $57 \mathrm{~mm}$; diam. rand : $85 \mathrm{~mm}$; diam. bodem : $38 \mathrm{~mm}$; oranjerode, goed gebakken klei ; matte, lichtrode vernis ; horizontale, omlopende groeflijn op de buitenwand.

Tweede helft $2 \mathrm{e}$ - $3 \mathrm{e}$ eeuw.

5. Randfragment van Dr. 45 (fig. 7) ; rode, zacht gebakken klei ; matte, rode vernis; leeuwenkopje in reliëf op de buitenwand.

Oost-Gallië (Rheinzabern?), 3e eeuw.

6. Bodemscherf van Pompejaans-rode schaal ; witgrijze, hard gebakken klei.

Tweede helft $1 e$ - midden $3 e$ eeuw.

c. Bewaarplaats : Kon. Musea voor Kunst en Geschiedenis; Brussel. Voorheen deel uitmakend van de verzameling G. Hagemans (Luik).

d. Bibliografie :

- Hagemans 1863, p. 444, nrs. 17-18.

- Juste 1864, p. 187, nr. BB. 19.

- De Clippele 1967, pp. 29, 267-271, 303-304, 306-307, fig. 163 166, 231.

- Bauwens-Lesenne 1962, p. 69 (verkeerdelijk onder Gent besproken).

Opmerking: de voorwerpen werden door De Clippele teruggevonden in de Kon. Musea voor Kunst en Geschiedenis te Brussel. Ze zijn daar geïnventariseerd onder de vindplaats Steenland. Nummers 3,4 en 5 dragen nog het oude inventarisnummer BB. 19, hetzelfde dat door Juste (-1864, p. 187) vermeld werd en dat toelaat tot de verzameling Hagemans op te klimmen. Vermelden we nog dat in de oudste publicatie (Hagemans 1863) de vindplaats van het aardewerk slechts zeer vaag werd omschreven als "hors de la porte d'Anvers" en (sic.) "hors de la Daemporte". De namen Steenland en Pannenhuis duiken slechts op in de inventaris van de Kon. Musea. Uit de beschrijvingen bij Hagemans en Juste, die het o.a. hebben over reliëfsigillata met voorstellingen van leeuwen, krijgers, jachtscènes enz., kunnen we afleiden dat een gedeelte van de verzameling Hagemans ofwel niet meer anwezig is in de Kon. Musea ofwel daar door De Clippele niet kon teruggevonden worden.

\section{Destelbergen?}

a. Hoogstwaarschijnlijk gevonden op de plaats Steenland (zie opmerking).

b. Drie flesjes uit aardewerk. Voor de hiernavolgende beschrijvingen steunen we op De Clippele (zie bibliografie).

1. Volledig bewaard exemplaar (fig. 5); bruingele kern en dito, geëffende buitenwand; h : $142 \mathrm{~mm}$; grootste breedte : $61 \mathrm{~mm}$; diam. opening : $26 \mathrm{~mm}$; diam. bodem : $36 \mathrm{~mm}$.

2. Flesje waarvan de monding en een deel van de hals ontbreken (fig. 6) ; beigegele kern, bruingele en geëffende buitenwand ; bewaarde hoogte : $100 \mathrm{~mm}$; grootste diam.: $60 \mathrm{~mm}$; diam. bodem : $27 \mathrm{~mm}$.

3. Flesje waarvan alleen het buikgedeelte is bewaard; beigegele' kern, bruingele en geëffende buitenwand; grootste breedte: $65 \mathrm{~mm}$. 
c. Bewaarplaats : Kon. Musea voor Kunst en Geschiedenis, Brussel (inv. nr. B. 333c). Voorheen deel uitmakend van de verzameling Hagemans (Luik).

d. Bibliografie :

- Hagemans 1863 , p. 446, nr. 49, PI. XII, 8.

- Juste 1864, p. 189, nr. BB. 59.

- Schuermans 1890 , p. 389.

- Bauwens-Lesenne 1962, p. 69 (hier onder Gent vermeld).

- De Clippele 1967, pp. 30, 271-273, 304, fig. 167-168.

Opmerking: in de hoofdbron (Hagemans 1863) wordt als vindplaats aangegeven : "hors de la porte d'Anvers et de la Daemporte". In nagenoeg dezelfde bewoordingen beschreef Hagemans de vindplaats van het aardewerk hierboven besproken onder nr. 21. Dit aardewerk, dat eveneens bewaard wordt in de Kon. Musea voor Kunst en Geschiedenis te Brussel, werd daar geïnventariseerd onder de plaatsaanduiding Steenland. Er bestaat dus een grote kans dat ook deze Gallo-Romeinse vondsten, gevonden buiten de Dampoort en deel uitmakend van de verzameling Hagemans, in Destelbergen, meer bepaald op Steenland, werden gevonden.

\section{Destelbergen}

a. In 1789 , op ongeveer $1 \mathrm{~m}$ diepte, op de plaats Berken-Zant.

b. Een hoop houtskool en ijzerfragmenten.met in de nabijheid 75 munten en nog wat verder nog eens 62 munten. Vermoedelijk gaat het om één enkele muntschat bestaande uit 136 sestertii en 1 dupondius. Het verband met de houtskoolconcentratie en de ijzerfragmenten is onduidelijk. Van 112 munten is de toewijzing bekend:

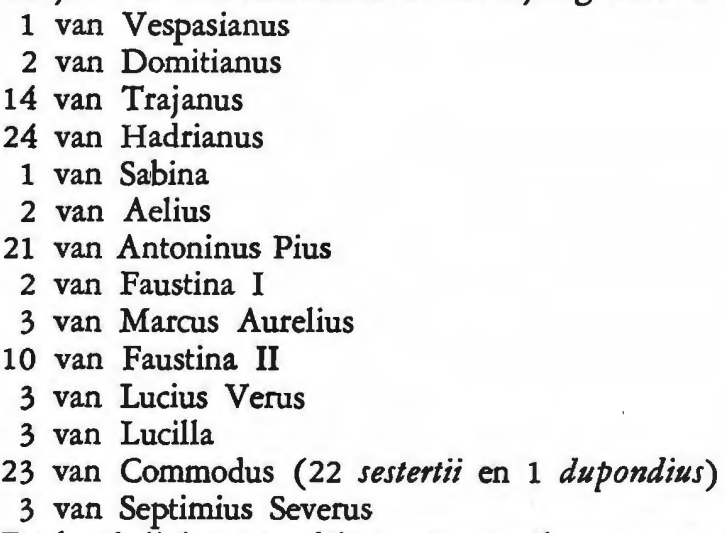

De beschrijving van drie munten ontlenen we aan De Bast ( -1804 , pp. $43-45$; - 1808, pp. 88-90) :

- Antoninus Pius. Keerzijde: TEMPLVM DIV. AVG. REST. COS. III. Tempel met 8 zuilen.

- Marcus Aurelius. Voorzijde : DIVVS M.ANTONINVS.

Keerzijde : CONSECRATIO. Keizer op wagen getrokken door 4 olifanten (fig. 8). 
- Septimius Severus. Keerzijde: P.M.TR.P.III.COS.II.P.P. Zittende Roma(?) met in de rechterhand een Victoria en in de linker een lans.

Deze munt is de jongste uit de reeks (195-196 n.C.).

c. Bewaarplaats : onbekend. In 1804 maakten voornoemde 112 munten deel uit van vier privé-verzamelingen waaronder deze van kanunnik M.J. De Bast (Gent).

d. Bibliografie :

- De Bast 1804, pp. 41-45.

- De Bast 1808, pp. 88-91, Pl. I, fig. XIV.

- Blanchet 1900, pp. 35, 264 nr. 674.

- Bolin 1926, (173).

- Van Gansbeke 1955, p. 28.

- Thirion 1967, p. 68 , nr. 62.

Opmerking: de plaats Berken-Zant, vermoedelijk een zandige opduiking, is op de kaart van Benthuys (1771) aangeduid onder de benaming Berckens Sandt (nr. 3 op de kaart). Ze bevindt zich op deze kaart ten zuiden van de Tietshammeerschen en ten noorden van de Meirsstraete, ten oosten van den tiets ofte bellegatdam en ten westen van de Daermstraete. Op het moderne stratennet kunnen we Berken-Zant als volgt localiseren: ten westen van de Kerkhamstraat (Daermstraete), ten oosten van de Hellegatstraat (den tiets ofte bellegatdam) en ten noorden van de Meerkenshamstraat (Meirsstraete).

Vermelden we nog dat Van Gansbeke (- 1955, p. 24) de vondst bij vergissing een tweede maal vermeldt onder de gemeente Dentergem.

\section{Gentbrugge (Gent)}

a. In 1867 of 1868 gevonden tijdens werken uitgevoerd voor de aanleg van de ringspoorweg aan de Neder-Schelde.

b. Blauwgroen glazen prismaflesje; $\mathrm{h}: 135 \mathrm{~mm}$.

c. Bewaarplaats : Kon. Musea voor Kunst en Geschiedenis, Brussel (inv. nr. B. 478).

d. Bibliografie :

- Van Dessel 1877, p. 96.

- de Loë 1937, p. 272.

- Mariën 1945, p. 19, voetnoot 2.

\section{Gentbrugge (Gent)}

a. Niet nader bepaalde vindplaats.

b. Munt van Nero.

c. Bewaarplaats : Kon. Musea voor Kunst en Geschiedenis, Brussel.

d. Bibliografie :

- Van Dessel 1877, p. 96.

\section{Gentbrugge (Gent)}

a. Op niet nader bepaalde vindplaats(en?).

b. Twee dakpannen. 
c. Bewaarplaats : Jacob van Maetlant-museum, Damme.

d. Bibliografie : - Trips 1956, p. 422.

\section{Sint-Amandsberg (Gent)}

a. Gevonden op niet nader omschreven vindplaatsen.

b. Drie bronzen munten (dupondii) : 2 van Trajanus en 1 van Antoninus Pius. De hiernavolgende beschrijving van de munt van Antoninus Pius (fig. 9) steunt op gegevens bij De Bast :

Voorzijde: ANTONINVS AVG. PIVS P.P. TR. P.XII. Kop van Antoninus Pius met lauwerkrans.

Keerzijde : MVNIFICENTIA AVG. COS. IIII. Olifant.

c. Bewaarplaats : onbekend.

d. Bibliografie :

- De Bast 1804, pp. 30-31.

- De Bast 1808, Pp. 31-32, Pl. I, fig. IV.

\section{Sint-Amandsberg - Destelbergen}

a. Buiten de Dampoort, in een veenderij.

b. Bronzen linkerarm (fig. 13) ; 1: $91 \mathrm{~mm}$; sterk beschadigd aan elleboog en vingertoppen. Het spits toelopende uiteinde laat vermoeden dat het stuk oorspronkelijk gemonteerd was in een beeldje. Het voorwerp heeft een veenpatina.

c. Bewaarplaats: Museum voor Oudheidkunde van de Rijksuniversiteit Gent.

d. Bibliografie :

- De Bast 1813, p. 199, Pl. III, fig. XII.

- Maertens de Noordhout 1938, p. 91, nr. 17.

Opmerking: De Bast beschrijft de vindplaats als volgt: „,... dans les tourbières hors de la porte d'Anvers, près du Mont-Saint-Amand". Volgens de bodemkaart van België, kaartblad Melle 55E (1963) kan het hier gaan om net grensgebied van Sint-Amandsberg en Destelbergen, meer in het bijzonder de plaatsen gelegen ten westen en ten noorden van de wijk Eenbeekeinde.

Naar vriendelijke mededeling van Mevrouw G. Faider, die over de Gallo-Romeinse bronzen uit België een corpus ter perse heeft, is het fragment wel degelijk GalloRomeins.

\section{Sint-Amandsberg (Gent)?}

a. Zou gevonden zijn te Sint-Amandsberg.

b. Bronzen Marsbeeldje (fig. 12) ; naaktfiguur van $85 \mathrm{~mm}$ hoogte. Bovenaan beschadigde Korinthische helm met vederbos; onder de helm zijn de haarlokken zichtbaar; gebogen en opgeheven rechterarm met door de hand het attributengat voor de lans.

c. Bewaarplaats: Museum voor Oudheidkunde van de Rijksuniversiteit Gent. 
d. Bibliografie :

- Den Duyts 1835, nrs. 8-9, fig. 9.

- Maertens de Noordhout 1938, p. 91, nr. 18.

Opmerking : de vroegste ons bekende vermelding van een bronzen Romeins beeldje uit Sint-Amandsberg hebben we aangetroffen in de geillustreerde handschrift-catalogus van de oudheidkundige verzamelingen van de Gentse universiteit. Dit handschrift, dat gedateerd is op 1835, werd opgesteld door F. Den Duyts. Onder de rubriek "Figures en bronze" vermeldt de auteur onder nr. 8 een Mercuriusbeeldje gevonden "hors de la porte d'Anvers près l'endroit appellé la montagne de SaintAmand" en deel uitmakend van de verzameling van wijlen kanunnik M.J. De Bast. De auteur verwijst verder naar fig. 8 van zijn catalogus. Nergens wordt echter in het Recueil van De Bast een Mercuriusbeeldje van Sint-Amandsberg vermeld. Daarentegen wordt door laatstgenoemd auteur een dergelijk beeldje beschreven en afgebeeld dat gevonden werd in Dendermonde (De Bast 1808, pp. 406-407, Pl. XIX, fig. IX). Nu stemt de afbeelding in dit werk vrij goed overeen met deze die door Den Duyts werd gegeven van het beeldje dat door hem op Sint-Amandsberg werd gelocaliseerd. De Heer J. Maertens de Noordhout, de latere dienstdoende conservator van de oudheidkundige verzamelingen van de Rijksuniversiteit, moet deze tegenstrijdigheid eveneens hebben opgemerkt want ter gelegenheid van de revisie van de Gentse verzameling in 1921 op basis van het handschrift van Den Duyts, geeft hij zijn opmerkingen weer op hetzelfde hs. Zo heeft hij onder de plaatsbepaling "Mont-Saint-Amand" in rode inkt de korrekte plaatsbepaling "Termonde" (Dendermonde) geschreven. Bij de beschrijving van een tweede "zogenaamd Mercuriusbeeldje, door Den Duyts behandeld onder nr. 9 met verwijzing naar fig. 9 en zonder vermelding van vindplaats, heeft Maertens de Noordhout in dezelfde rode inkt "Mont-Saint-Amand" (Sint-Amandsberg) toegevoegd. In een handschrift-inventaris van $H$. Van Duyse, gedateerd op 7-2-1888 (Van Duyse 1888), die de voorwerpen vermeldt die (voor het merendeel tijdelijk) van de universiteit Gent werden overgedragen aan het Oudheidkundig museum van de stad Gent, lezen we onder nr. 1989: "statuette en bronze. Mercure nu, tête casquée, trouvée à Mont Saint-Amand. h. 0.10". De afmeting $(10 \mathrm{~cm})$ stemt overeen met het onder nr. 8 beschreven Mercuriusbeeldje in het hs. Den Duyts, dat door dezelfde auteur, zoals we gezien hebben, verkeerdelijk op Sint-Amandsberg werd gelocaliseerd. Vermoedelijk heeft Van Duyse dan ook de fout van Den Duyts overgenomen. In de gedrukte catalogus van 1938 van de hand van Maertens de Noordhout ( -1938 , p. 91, nr. 18) bevestigt deze auteur zijn kritiek van 1921 op het hs. Den Duyts. Samenvattend kunnen we zeggen dat het Mercuriusbeeldje, dat door Den Duyts op Sint-Amandsberg werd gelocaliseerd, in werkelijkheid gevonden is in Dendermonde en deel heeft uitgemaakt van de verzameling De Bast vooraleer het zijn plaats kreeg in het universiteitsmuseum. Maertens de Noordhout geeft daarenboven als zijn mening te kennen dat het onder nr. 9 vermelde beeldje bij Den Duyts (fig. 12) in werkelijkheid een Marsbeeldje is en op Sint-Amandsberg werd gevonden. De eerste rechtzetting kunnen we bijtreden. Een vergelijking van het origineel bewaard in het museum van de Rijksuniversiteit met fig. 9 bij Den Duyts, bewijst dat het hier inderdaad om een Mars- en niet om een Mercuriusbeeldje gaat. Op grond van welke argumenten Maertens de Noordhout de vindplaats van dit Marsbeeldje op SintAmandsberg localiseert, is ons daarentegen niet bekend.

\section{B. VARIA EN PERSONALIA}

- Van 29 april tot 16 mei 1978 ging in de Raadzaal van het Gemeentehuis van Destelbergen een tentoonstelling door over „Oudheidkundige Opgravingen te Destelbergen". De tentoonstelling werd ingericht door de Destelbergse Kunst- en Kultuurkring "Rond de Damvallei" in samenwerking met het Seminarie voor Archeologie van de Rijksuniversiteit Gent. 
- Van het tijdschrift Stadsarcheologie, uitgave van de Gentse Vereniging van stadsarcheologie, verschenen nrs 1 en 2 van de tweede jaargang (1978). Hierin worden enkele recente vondsten vermeld, die voor onze kroniek van belang zijn, nl. een neolithische bijl gevonden tijdens een noodopgraving van 1977 op het afbraakterrein aan het Dobbel Slot te Gent (Stadsarcheologie 2, 1978, 1, p. 23), een Romeins brandrestengraf in de Pekelharing te Gent ( $-2,1978,2$, p. 14) en een silex-pijlpunt uit St.-Amandsberg (- 2, 1978, 2, p. 26).

- Door de Dienst voor Archeologie en Historische Monumenten Gent en de Nationale Dienst voor Opgravingen te Brussel werden op 17 en 18 maart 1978 contactdagen georganiseerd onder het motto "Middeleeuwen 78". De bijeenkomst ging door in het Gentse Centrum voor Kunst en Cultuur. Een gestencilde brochure van 56 pp. geeft een samenvatting weer van de referaten. Onderwerpen over archeologie in Gent werden behandeld door P. Raveschot (De vroeg-middeleeuwse ceramiek in Gent), J. Vandenhoute (Stadsarcheologie te Gent) en G. De Smet (Noodopgraving naar het Tempelhof te Gent).

- Zopas verscheen de achtste reeks van Oudheidkundige Opgravingen en Vondsten in Oost-Vlaanderen (O.O.V.O. VIII). In deze band werd o.a. het aanvullende en eindverslag gepubliceerd over de opgravingen te Destelbergen - Eenbeekeinde, opgravingsvlakken B, C. D en F. Het volledige verslag over opgravingsvlak $\mathrm{E} z \mathrm{zal}$ in een volgende aflevering gepubliceerd worden.

\section{LIJST VAN DE AFBEELDINGEN}

Situatiekaart. Wijkindeling: 1. ex. Wachtebeke ; 2. St.-Kruis-Winkel ; 3. Klein-Gent ; 4. Kluizen ; 5. Mendonk ; 6. ex. Zaffelare ; 7. Desteldonk ; 8. Oostakker ; 9. Wondelgem; 10. Mariakerke; 11. St.Amandsberg ; 12. Drongen; 13. Gentbrugge; 14. Ledeberg; 15. Afsnee ; 16. St.-Denijs-Westrem; 17. Zwijnaarde.

1-4, 7. Aardewerk uit terra sigillata, Destelbergen. Tekeningen naar De Clippele 1967, fig. 163-166, 231.

5-6. Aardewerkflesjes, Destelbergen. Tekeningen naar De Clippele 1967, fig. 167-168.

8. Sestertius van Marcus Aurelius, Destelbergen. Tekening naar De Bast 1808, PI. I, fig. XIV.

9. Dupondius van Antoninus Pius, St.-Amandsberg. Tekening naar De Bast 1808, Pl. I, fig. IV.

10-11. Stempels op terra sigillata, Destelbergen. Tekeningen naar De Clippele 1967, fig. $230,232$.

12-13. Bronzen Marsbeeldje, St.-Amandsberg. Cliché's M. Desittere.

Uittreksel van kaart van Carolus Benthuys (1771) met de aanduiding van het opgravingsterrein van het Seminarie voor Archeologie Gent (nr. 1), van de plaats Steenland met vondsten gedaan in de 19e eeuw (nr. 2) en van de plaats Berken-Zant, waar in 1789 de muntschat werd gevonden (nr. 3). 


\section{BIBLIOGRAFISCHE AFKORTINGEN}

Bauwens-Lesenne $1962=$ M. Bauwens-Lesenne, Bibliografiscb repertorium der oudbeidkundige vondsten in Oost-Vlaanderen, Oudheidkundige Repertoria II, Brussel, 1962.

Benthuys $1771=$ Carolus Benthuys, Figurative kaart van alle de thiendebaere landen gelegen binnen de prochie van Destelberge, ressort der Casselrije van den Audenburg te Gbendt, gemaekt ten verzoeke van Anselmus Balde, ontvanger der exempte abdije van Sinte Pieters, nevens Gbendt, door Carolus Bentbuys, gezworen landmeter geadmitteerd door den Raede van Vlaenderen, 7 mei 1771 (origineel bewaard in het Rijksarchief te Gent, Fonds Destelbergen : kaarten en plans, nr. 345).

Blanchet $1900=\mathrm{A}$. Blanchet, Les trésors de monnaies romaines et les invasions germaniques en Gaule, Parijs, 1900.

Bolin $1926=$ St. Bolin, Fynden av Romerska Mynt $i$ det Fria Germanien, Lund, 1926.

Boon $1973=\mathrm{M}$. Boon, Kruiken, kruikamforen en amforen gevonden te Destel. bergen. Typologie en chronologie, Gent, 1973 (onuitgegeven licentiaatsverhandeling).

De Bast $1804=$ M.J. De Bast, Recueil d'antiquités romaines et gauloises trouvées dans la Flandre proprement dite avec désignation des lieux où on les a découvertes, Gent, 1804.

De Bast $1808=$ M.J. De Bast, Recueil d'antiquités romaines et gauloises trouvées dans la Flandre proprement dite avec désignation des lieux où on les a découvertes, 2e uitgave. Gent, 1808.

De Bast 1813 = M.J. De Bast, Second supplément au Recueil d'antiquités romaines et gauloises, contenant la description de l'ancienne ville de Bavai et de Famars, Gent, 1813.

De Clippele $1967=$ L. De Clippele, Het Gentse en bet Meetjesland in de Romeinse tijd. Het verband tussen de bewoning en de bodemgesteldbeid, Gent, 1967 (onuitgegeven licentiaatsverhandeling).

De Laet $1966=\mathrm{S}$.J. De Laet, Etudes sur la céramique de la nécropole GalloRomaine de Blicquy (Hainaut) II. La poterie dite "savonneuse", Helinium, 6, 1966, pp. 3-25.

De Laet $1969 \mathrm{a}=$ S.J. De Laet, Nieuw licht op de oorsprong van Gent, Spiegel Historiael 4, 1969, pp. 133-140.

De Laet $1969 \mathrm{~b}=\mathrm{S} . \mathrm{J}$. De Laet, Les fouilles de Destelbergen et les origines gallo. romaines de la ville de Gand, Archeologia (Parijs), 30, 1969, pp. 57-69.

De Laet $1977=$ S.J. De Laet in Graven naar Gents Verleden, Gent, 1976, pp. 15-22, $48-49$.

De Laet-Thoen $1969=$ S.J. De Laet - H. Thoen, Etudes sur la céramique de la nécropole Gallo-Romaine de Blicquy (Hainaut) IV. La céramique "d̀ enduit rouge-pompéien", Helinium 9, 1969, pp. 28-38.

De Laet-Thoen-Van Doorselaer $1970=$ S.J. De Laet, H. Thoen en A. Van Doorselaer, La tombe collective de la nécropole gallo-romaine de Destelbergen-lez-Gand (Flandre orientale), Helinium 10, 1970, pp. 3-30.

De Laet-Van Doorselaer 1969 = S.J. De Laet-A. Van Doorselaer, Lokale ijzerwinning in westelijk België in de Romeinse tijd, Meded. van de Koninklijke Academie voor Wetenschappen, Letteren en Schone Kunsten van België, Klasse der Letteren 31, 4, 1969.

de Loë = A. de Loë, Musées royaux d'art et d'bistoire à Bruxelles, Belgique Ancienne. Catalogue descriptif et raisonné III. La Période Romaine, Brussel, 1937.

Den Duyts $1835=$ F. Den Duyts, Catalogue A. Figures en Bronze, 26-9-1835 (handschrift bewaard in het Seminarie voor Archeologie, Gent). 
Desittere $1974=$ M. Desittere, Archeologische Kroniek, Handelingen der Maatschappij voor Geschiedenis en Oudheidkunde te Gent 28, 1974, pp. 141-158.

Desittere $1977=$ M. Desittere, Archeologische Kroniek, Handelingen der Maatschappij voor Geschiedenis en Oudheidkunde te Gent 31, 1977, pp. 225-239.

Hagemans $1863=$ G. Hagemans, Un cabinet d'amateur. Notices archéologiques et description raisonnée de quelques monuments de baute antiquité, Luik-Leipzig, 1863.

Juste $1864=$ Th. Juste, Catalogue des collections composant le Musée Royal d'Antiquités, d'Armures et d'Artillerie (Bruxelles), précédé d'une notice bistorique, Brussel, 1864.

Maertens de Noordhout $1938=\mathrm{J}$. Maertens de Noordhout, Catalogue du musée des antiquités de l'université de Gand, St.-Amandsberg, 1938.

Mariën $1945=$ M.E. Mariën, Note sur une bouterolle de l'âge du bronze découverte à Gentbrugge, Bulletin des Musées royaux d'Art et d'Histoire, 3e reeks, 17, 1945, pp. 19-21.

O.O.V.O. II = S.J. De Laet, J.A.E. Nenquin, P. Spitaels en A. Van Doorselaer, Nieuwe Oudbeidkundige Opgravingen en Vondsten in Oost-Vlaanderen, Kultureel Jaarboek voor de Provincie Oost-Vlaanderen 12, 1958 (1961), II, pp. 3-99.

O.O.V.O. III = S.J. De Laet, A. Van Doorselaer en P. Spitaels, Oudbeidkundige Opgravingen en Vondsten in Oost-Vlaanderen, derde reeks, Kultureel Jaarboek voor de Provincie Oost-Vlaanderen 17, 1963 (1964), II, pp. 4-83.

O.O.V.O. IV $=$ S.J. De Laet, A. Van Doorselaer, M. Desittere en H. Thoen, Oudbeidkundige Opgravingen en Vondsten in Oost-Vlaanderen, vierde reeks, Kultureel Jaarboek voor de Provincie Oost-Vlaanderen 19, 1965 (1967), II, pp. 3-172.

O.O.V.O. V $=$ S.J. De Laet, A. Van Doorselaer, M. Desittere en H. Thoen, Oudbeidkundige Opgravingen en Vondsten in Oost-Vlaanderen, vijfde reeks, Kultureel Jaarboek voor de Provincie Oost-Vlaanderen 23, 1969 (1970), II, pp. 3-189.

O.O.V.O. VII = S.J. De Laet, J. Nenquin, A. Van Doorselaer, M. Desittere, A. Gautier, $\mathrm{H}$. Thoen, F. Verhaeghe en M. Rogge, Oudbeidkundige Opgravingen en Vondsten in Oost-Vlaanderen VII, Kultureel Jaarboek voor de Provincie Oost-Vlaanderen, Bijdragen, Nieuwe Reeks - Nr 2, 1976, 215 pp.

O.O.V.O. VIII $=$ S.J. De Laet, A. Van Doorselaer, M. Desittere, H. Thoen, F. Verhaeghe en M. Rogge, Oudheidkundige Opgravingen en Vondsten in Oost-Vlaanderen VIII, Kultureel Jaarboek voor de Provincie Oost-Vlaanderen, Bijdragen, Nieuwe Reeks - Nr. 6, 1978, 136 pp.

Schuermans $1872=\mathrm{H}$. Schuermans, Antiquités trouvées en Belgique, Bulletin des Commissions royales d'Art et d'Archéologie 11, 1872, pp. 23-49.

Schuermans $1890=\mathrm{H}$. Schuermans, Antiquités trouvées en Belgique, Bulletin des Commissions royales d'Art et d'Archéologie 29, 1890, pp. 361-424.

Thirion $1967=\mathrm{M}$. Thirion, Les trésors monétaires gaulois et romains trouvés en Belgique, Brussel, 1967.

Trips 1956 = E. Trips, Het Jacob van Maerlant-Museum te Damme bij Brugge, L'Antiquité Classique 25, 1956, pp. 421-422.

Van Dessel $1877=\mathrm{C}$. Van Dessel, Topographie des voies romaines de la Belgique. Statistique archéologique et bibliographie, Brussel, 1877.

Van Doorselaer $1969=$ A. Van Doorselaer, Typische Gallo-Romeinse brandrestengraven in de Scheldevallei, Helinium 9, 1969, pp. 118-137. (= Studia Historica Gandensia 128).

Van Doorselaer $1971=$ A. Van Doorselaer, Primitive Eisenverbüttung in Belgien, Early Medieval Studies 3, Antikvariskt arkiv 40, Stockholm, 1971, pp. 31-36. 
Van Duyse $1888=\mathrm{H}$. Van Duyse, Inventaire des objets d'art et antiquités appartenant à l'université de Gand transférés au Musée d'Arcbeologie (handschrift van 7-2-1888 bewaard in de Centrale Bibliotheek van de Rijksuniversiteit Gent).

Van Gansbeke $1955=\mathrm{P}$. Van Gansbeke, Les trésors monétaires d'époque romaine en Belgique, Revue belge de numismatique et de sigillographie 101, 1955, pp. 5-44.

Verhelst $1847=\mathrm{B}$. Verhelst, Cabinet Versturme. Catalogue des curiosités formant le cabinet de feu M. Versturme-Roegiers, consistant en livres, manuscrits et documents bistoriques, sculptures, tableaux, dessins et estampes, médailles, antiquités, armes et armures, etc., Gent, 1847.

Vynckier $1966=\mathrm{J}$. Vynckier, Onderzoek en conservatie van bet vlechtwerk uit een Romeinse waterput te Destelbergen, Bulletin van het Koninklijk Instituut voor het Kunstpatrimonium 8, 1965 (1966), pp. 167-171.

Wankenne $1972=A$. Wankenne, La Belgique à l'époque romaine. Sites urbains, villageois, religieux et militaires. Nationaal Centrum voor Oudheidkundige Navorsingen in België, reeks C III, Brussel 1972, 208 pp. 


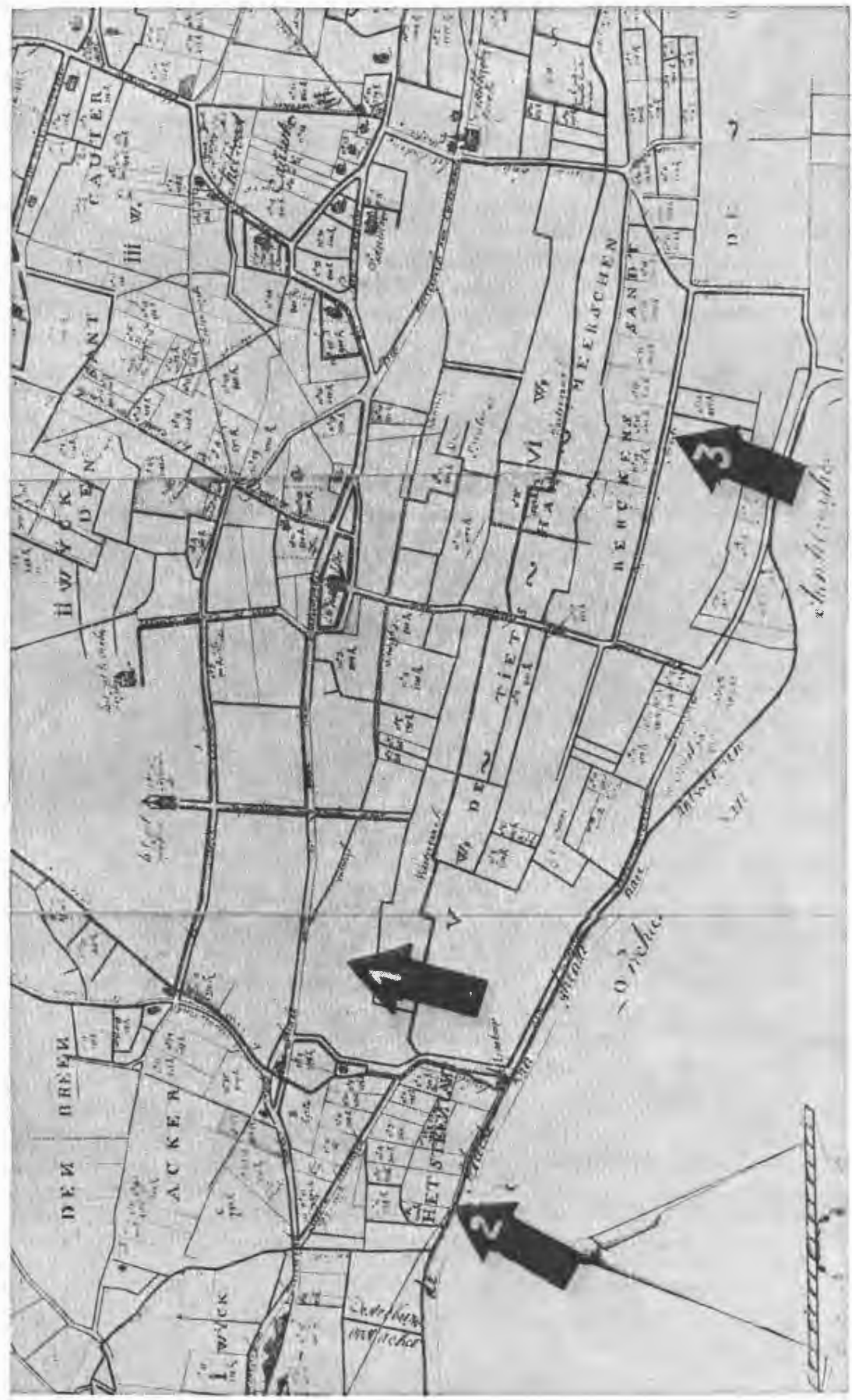



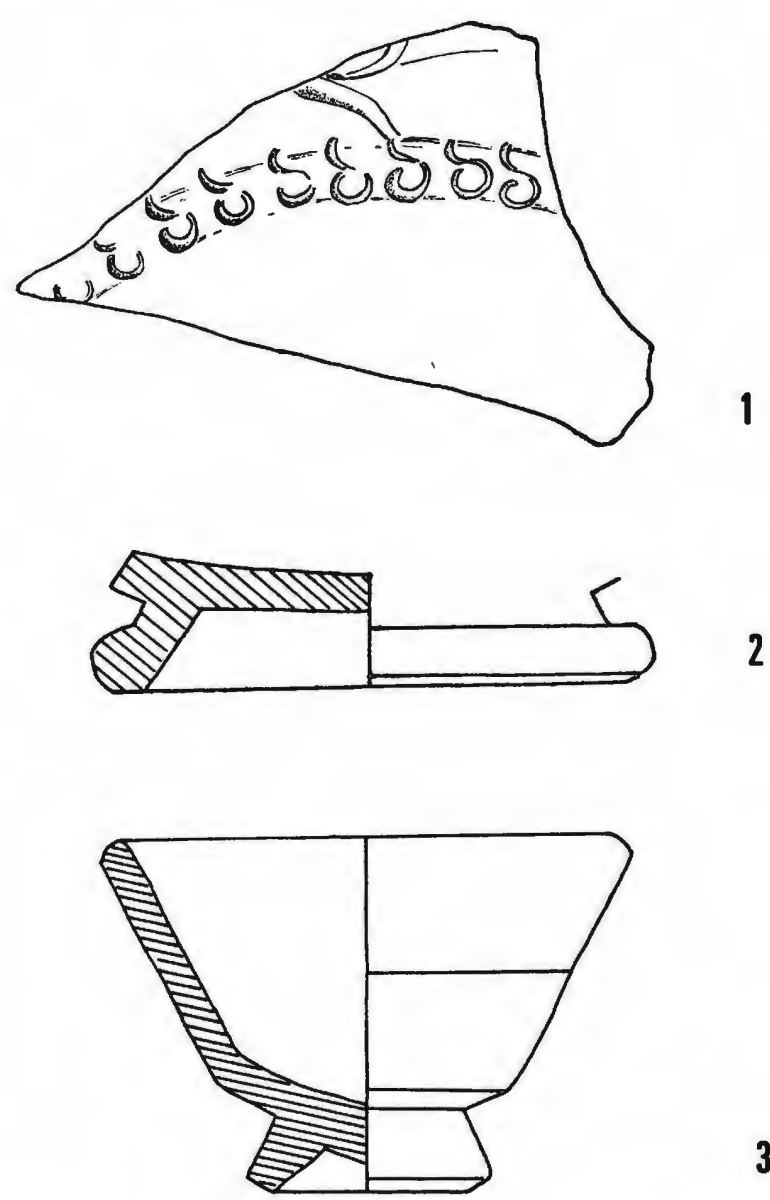

3
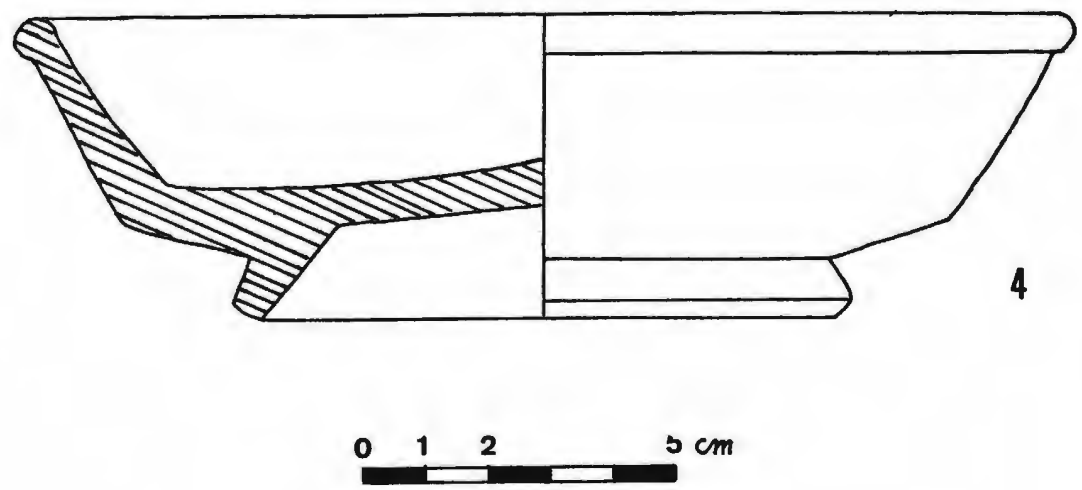


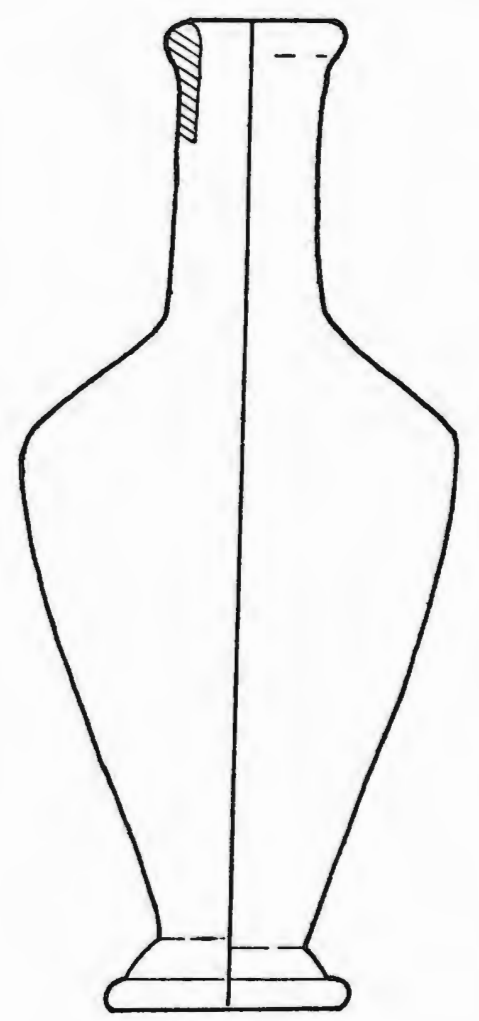

\section{5}
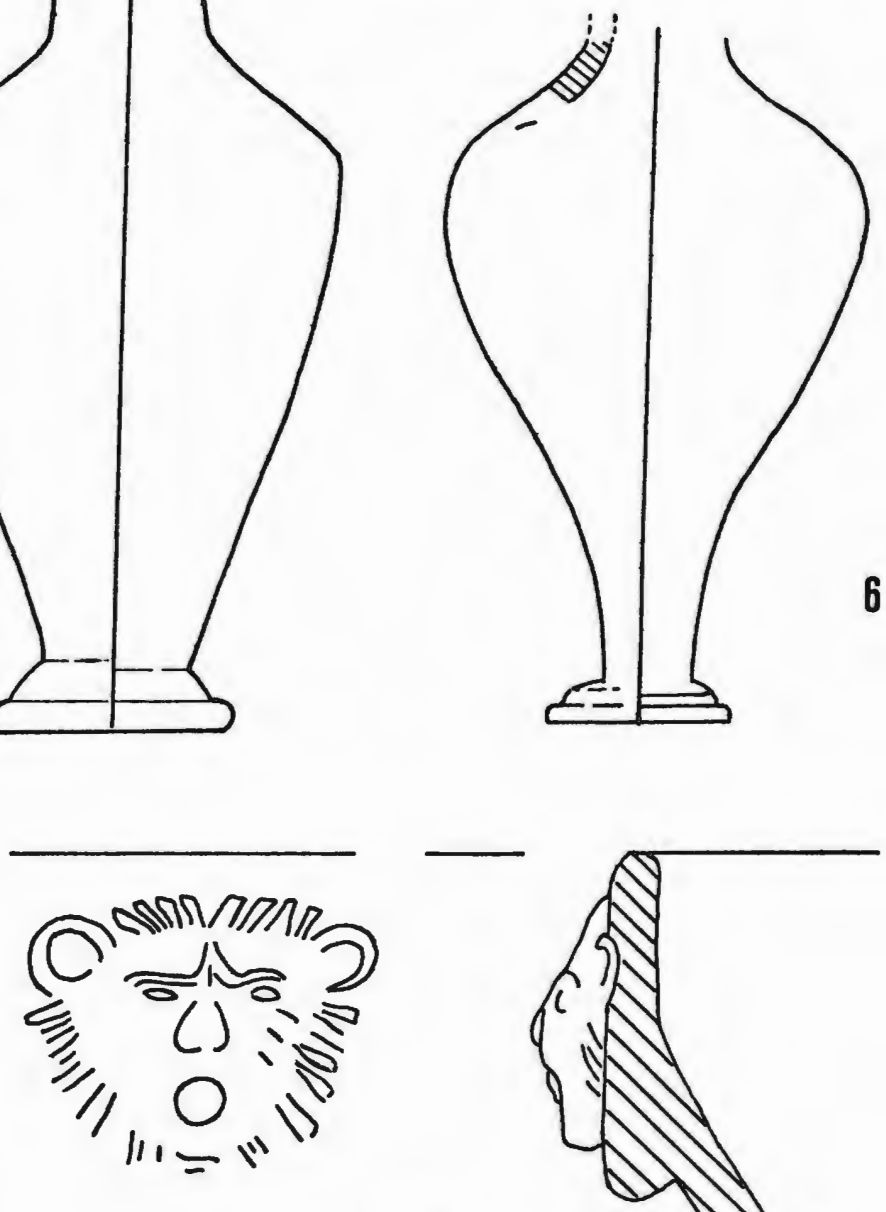

7

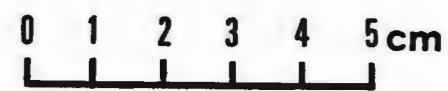



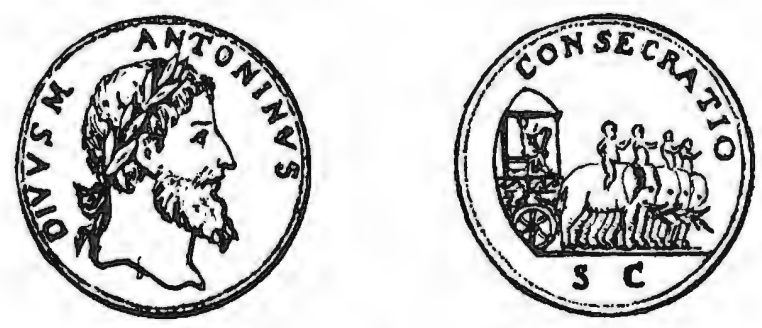

8
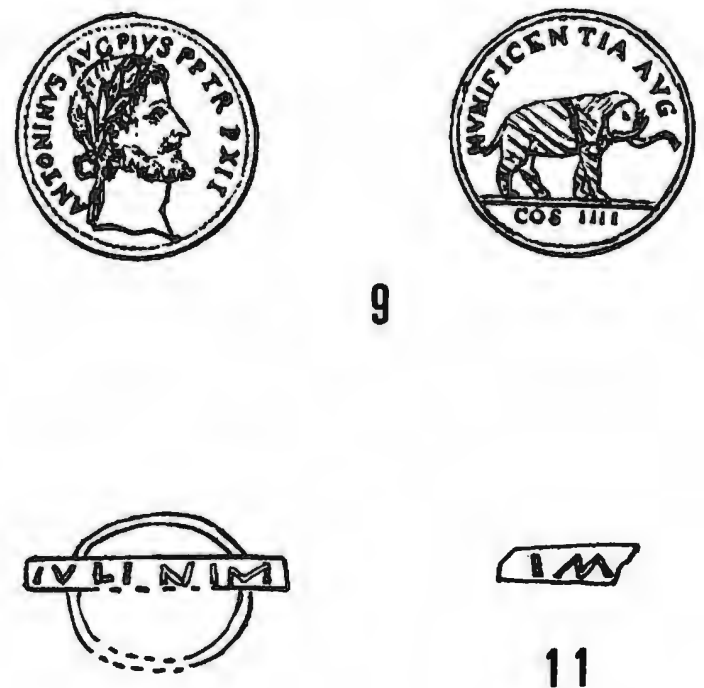

11

10

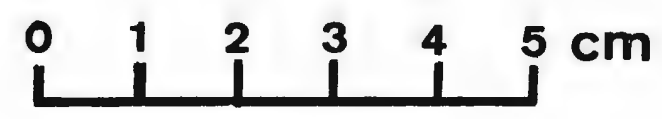



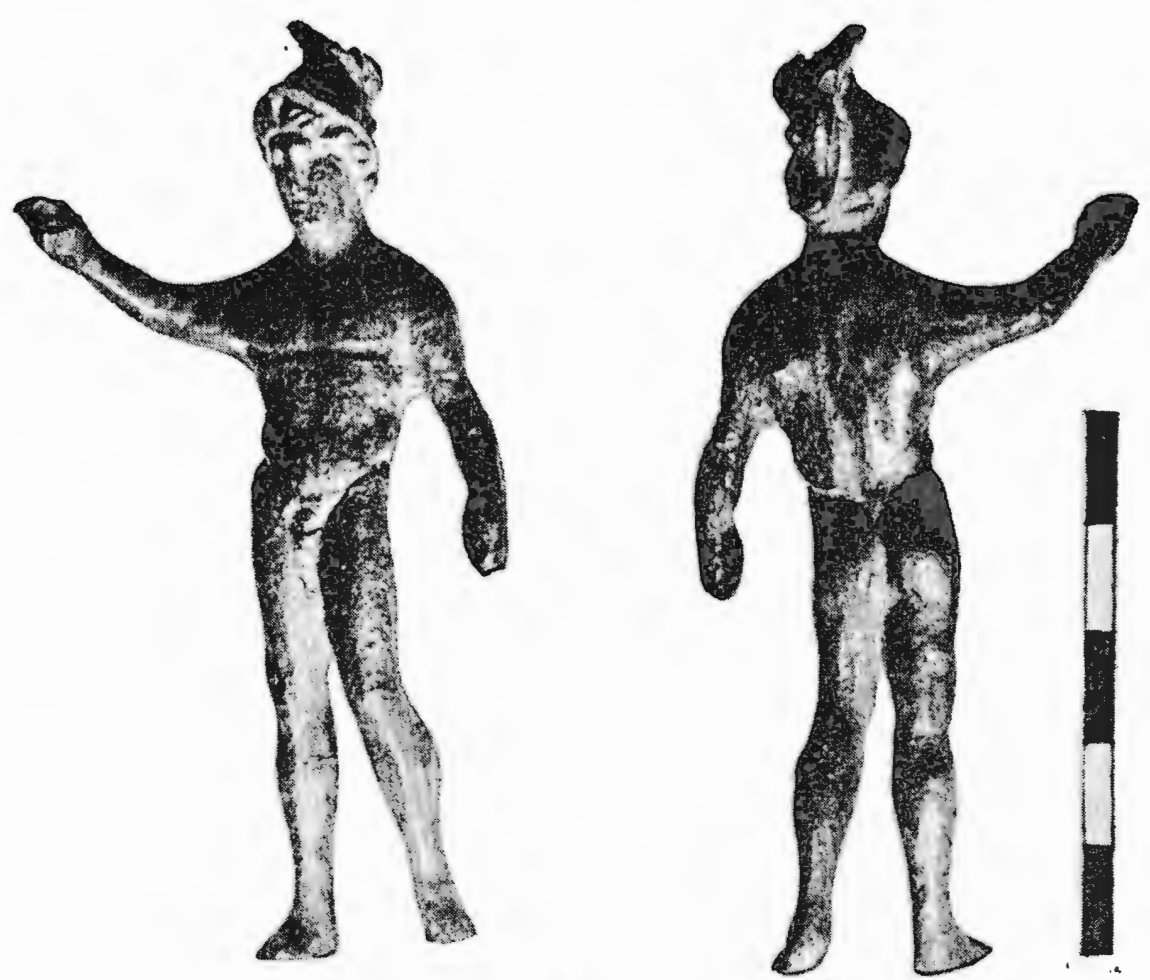

12

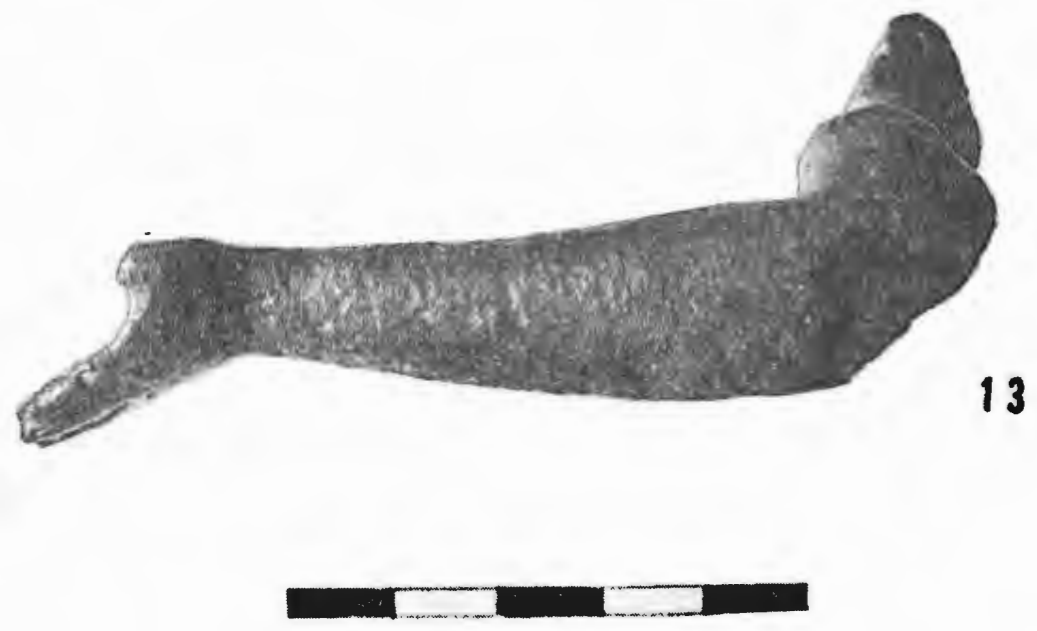

